Izvorni naučni članak

UDK: 616.981.45(497.11)"1521/1850"

ID: 212278540

\author{
Marija Kocić \\ Odeljenje za istoriju \\ Filozofski fakultet, Univerzitet u Beogradu \\ Čika Ljubina 18-20, 11000 Beograd, Srbija \\ marijakocich@gmail.com

\section{Haris Daǰ̌} \\ Odeljenje za istoriju \\ Filozofski fakultet, Univerzitet u Beogradu \\ Čika Ljubina 18-20, 11000 Beograd, Srbija \\ hdajc@f.bg.ac.rs
}

\title{
KUGA U RANOMODERNOM BEOGRADU: UZROCI, STRAHOVI I POSLEDICE*
}

\begin{abstract}
Apstrakt: Rad analizira pojavu jedne od najznačajnijih epidemija u ranomodernoj epohi, koja je po ondašnje stanovništvo imala ne samo zdravstvene, već i moralne posledice. U izradi rada u prvom redu korišćeni su putopisi i memoarska literatura, čiji su tvorci savremenici koji su se u trenutku kada je kuga pustošila Beograd zatekli u njemu.
\end{abstract}

Ključne reči: kuga, Osmansko carstvo, karantin,

$\mathrm{Ne} \mathrm{MeSH}$ : Beograd, sanitarni kordon

Key words: plague, Ottoman Empire, quarantine

Non MeSH: Belgrade, sanitary cordon

Od kada je ušao u sastav Osmanskog carstva (1521) Beograd je svoju sudbinu vezao za ovu državu, koja se do tada učvrstila na velikom delu Balkana. Jedno vreme je imao status krajišta, dok je služio kao baza odakle se kretalo u napade u Ugarsku sve do 1541, kada je formiran budimski elajet. Osmanlije su postepeno uspele da gradu na ušću Save u Dunav nametnu svoju vlast, ali i kulturu [1,2]. Od tada počinje

\footnotetext{
* Rad predstavlja rezultat naučno-istraživačkog projekta br. 177009: „Modernizacija zapadnog Balkana”, finansiranog od strane Ministratsva prosvete, nauke i tehnološkog razvoja Republike Srbije.
} 
da raste broj njegovog muslimanskog stanovništva, ali se u isti doseljavaju Jermeni i Jevreji, povedeni razvojem trgovine, koja je stvaranjem pax turcica-e dobila poseban zamah. [1 pp164 -202]

U Evropi se pandemija kuge (lat. pestis) prvi put javlja 1347. u Mesini (Sicilija), što je navelo pojedine istraživače da njeno poreklo potraže na Istoku. Moderna istraživanja otkrila su da je izaziva bakterija Yersina pestis, mikroorganizam duguljastog oblika, sposoban za izuzetno brzo reprodukovanje. Rapidnom širenju kuge doprinela je činjenica da pomenuta bakterija egzistira u telu insekta Xenopsilia cheopsis, koga prenose pacovi. Kuga poznata u istoriografiji kao Crna Smrt uspela je da za samo nekoliko godina (1347-1351) odnese trećinu stanovništva Evrope. [3 p46] Od tada, narednih nekoliko vekova kuga je predstavljala pošast na čiji se pomen među stanovnicima stvarala panika, koja se, kako je epidemija odmicala, pretvarala u masovnu histeriju, odavajući nemoć običnog čoveka prema pošasti za koju nije imao leka.

U izvorima osmanske provijencije kuga se pominje pod nazivom taun i veba. Termin veba se koristio za najekstremnije slučajeve kuge, koje su gotovo po pravilu završavali smrtnim ishodom, ali se mogao primeniti i na druge zarazne bolesti. Izraz taun koristio se isključivo za žlezdanu kugu. Prema pojedinim tumačenjima, taun je bio jedan od oblika vebe, ali svaki slučaj vebe nije morao biti taun. [4 p32] Na osnovu arhivske građe, čiji su tvorci diplomate koje su dobar deo života provele u osmanskoj državi, donekle se može rasvetliti i ritmika pojave i ubojitost kuge za pojedine delove ove države. Tu se u prvom redu misli na Carigrad, Jedrene, ali i Izmir, Alepo i druge levantske gradove, gde su evropske države uspele da uspostave svoju konzularnu mrežu. Na osnovu ove građe može se sa sigurnošću tvrditi da je vrhunac kuge padao u razdoblju od juna do septembra, kada je ona odnosila i najveći broj žrtava. [5] Nakon ovoga ona bi se izvrgla u vrstu zloćudne groznice, koja je obično trajala do hladnih zimskih dana. Međutim, ova vrsta izvora nedostaje za ranomoderni Beograd, zbog čega su i istraživači usmereni da korišćenjem drugih istorijskih vrela pokušaju da rekonstruišu njenu pojavu i kulminaciju.

Cirkulacija ljudi kroz trgovinu, koja je povezivala Daleki istok sa Evropom, posebno je pogodovala pojavi i širenju epidemija, što predstavlja jednu od najnegativnijih posledica, koje je osmansko osvajanje donelo gradu. Prema konstataciji Bogumila Hrabaka, ,zaraze su nekoliko puta više nego svi i spoljni i unutrašnji ratovi odnosili života i privredno aktivnog i izdržavanog dela stanovništva". [6 p19] Od kuge je više stradalo gradsko stanovništvo od seoskog, tako da su upravo gradovi podnosili najveće žrtve njihovog izbijanja. U drugom radu ovaj istoričar naveo je da „ukoliko bi kakva veća epidemija odnela samo $10 \%$ gradskog stanovništva za svega nekoliko nedelja nastala bi značajna praznina, koja bi se ogledala u privrednom, društvenom i drugim domenima života". [7 p5]

Osmansko carstvo bilo je daleko od postignuća pojedinih evropskih država na polju suzbijanja kuge. U tome su prednjačile Venecija, [3 pp45-65] Dubrovnik, ali i pojedine zapadne države, koje na pragu ranomodene epohe počinju sa uvođenjem 
karantina kao mere na suzbijanju širenja kuge. Osmansko carstvo za ovim je zaostajalo. Niko se od vodećih ljudi u ovoj državi nije preterano trudio da prihvati tekovine tadašnje zdavstvene kulture, koje je Zapad plasirao. Na ovo je uticao stav verskih učenjaka (uleme, pre svih šejh ul-islama), koji su preko svojih mišljenja (fetve), kao jedino sredstvo u borbi sa kugom zagovarali bekstvo. [8 p3] U opravdanju ove mere pozivali su se na tradiciju prvih dana kalifata, koja navodi da se i kalifa Omar (634644) spasio kuge bekstvom. [8 p3] Međutim, u ranom islamskom periodu pojavili su se ljudi, koji su se zanimali za medicinu, i koji u kugi nisu prepoznavali mističnu silu, na koju su kao odgovor preporučivali magične rituale. I pored toga, dugo je među ulemom opstalo stanovište da u kugi prepoznaju jednu od Božijih kazni - i to onu najgoru. [9]

Čuveni legalista Ebusud efendija nalagao je sredinom XVI veka svojim vernicima da se ne zadržavaju u kugom zahvaćenim oblastima. [4 p35] Prema drugim istraživačima, ulema u nametanju stava prema kugi nije bila jednoglasna, mada su najvećim delom u njoj preovladavali stavovi koji su zagovarali istaknuti muslimanski učenjaci iz XIV veka. [10 p177] Ebusud efendija, koji se nalazio na čelu uleme u vrhuncu osmanske države (1545-1574), sa jedne strane preporučivao je muslimanima da na pojavu kuge pošalju žene i decu u sigurnija mesta, uključujući i hrišćanska sela, dok je s druge prigovarao ulemi bekstvo, pod izgovorom da time napuštaju svoje vernike. [10 p173] Ugledni muslimanski učenjak ibn-Salum (umro 1670), glavni lekar Mehmeda IV (1648-1687), uzrok pojavi kuge tražio je u objašnjenju koje je dao čuveni antički lekar Galen da se ona javljala usled trulosti vazduha (mijazma), koji se potom uvlačio u ljudsko telo. [10 p177]

Od mera koje je Porta preduzimala na sprečavanju širenja kuge najznačajnija je karantin, [11] koji je po prvi put uveden 1838. [8 p3] Podatak koji iznosi Birsen Bulmuš ujedno ukazuje da je tokom cele ranomoderne epohe Osmansko carstvo odbijalo da prihvati tekovine ondašnje zapadne medicine. Ova činjenica je uticala da ono ostane latentno izvoriše kuge, koja je lako kružila od jedne do druge njegove granice, uglavnom prenošena vojskom, ili putem trgovačkog saobraćaja. Zbog toga je i smrtnost usled pojave epidemije bila mnogo veća, nego u pojedinim delovima Evrope. Ista činjenica figurira i kao glavni imenitelj mera koje su države koje su održale kontakte sa Osmanskim carstvom preduzimale na suzbijanju pojavi i širenju epidemije. U Veneciji je gotovo do samog kraja opstala praksa da se za brodove koji su dolazili sa Levanta primenjuju strože mere na izdržavanju karantina. [12 p19] Međutim, ovo je predstavljalo relativno slabu meru predostrožnosti, dok sanitarna služba u ovom periodu nije postojala.

Istraživanje ritmike kuge na Balkanu tokom ranomodernog perioda ograničena su usled nepostojanja izvora na koje bi se istraživač sa sigurnošću mogao pozvati. Iako se za XVI vek mogu uzeti kao polazna osnova popisni defteri, koje je vlast sastavljala u cilju oporezivanja stanovništva, prelaskom na drugačiji sistem oporezivanja tokom XVII veka izmenjen je i princip po kome je stanovništvo popisivano. Zbog toga i statističko praćenje određenih pojava tokom XVII i XVIII veka zaostaje 
pouzdanošću i određenim kvalitetom za prethodnim stolećem. Ne mogu se ispratiti ni fluktuacije u broju stanovnika izazvane epidemijama, u prvom redu kugom, koja je do sredine XVIII veka ostala glavna determinanta koja je uticala na mortalitet stanovništva. [4 p32]

Već prilikom osvajanja Beograda (1521) javljaju se slučajevi obolelih od kuge. [13 p74] Može se pretpostaviti da je njen prenosilac bila vojska, koja je opsedala gradske zidine. Druga velika epidemija kuge koja je pogodila Beograd u XVI veku izbila je 1579. [13 p137] Novi talas kuge pogodio je grad 1599. takođe kada je u njemu boravila vojska, koja je čekala da bude poslata u Ugarsku. [8 p347] Uopšteno gledano, tokom XVI veka Beograd nije bio često pogođen kugom. Na to upućuje nekoliko činjenica. Grad je tokom pomenutog veka iskusio demografsku ekspanziju svojstvenu celoj Evropi i Maloj Aziji istog perioda. Ova činjenica, dokazana u mnogobrojnim radovima, može se uzeti kao neosporna istina.

Problem istraživanja kuge u Beogradu tokom narednih vekova skopčan je sa nepostojanjem izvora, ali i mnogo većom frekventnošću, sa kojom se kuga počinje javljati. Na ovaj način kuga bi, pored ratova, predstavljala bitan faktor u regresiji ukupnog broja stanovnika ne samo u Evropi, nego i na Balkanu, uključujući i Beograd. Prema opisu titularnog biskupa Skadra, fra Antonija de Đorđija (bez datuma, ali se pretpostavlja da potiče iz prve polovine XVII veka), Beograd je imao 120.000 stanovnika, među njima Turaka, pravoslavaca, Jevreja i drugih nacija. [14 p12] Međutim, anonimni autor u pratnji francuskog ambasadora de La Ea naveo je (1621) da su većinu njegovih stanovnika činili hrišćani. [15 p165]

U skorijem istraživanju dokazano je da je kuga, koja je Evropu pustošila od 1613. do 1635, pripada ciklusu određenom kao „indijski”, čime je kao izvorište označen Indijski potkontinent. Drugi ciklus koji počinje 1636. i traje do 1666. određen je kao „levantski”, dok je Carigrad označen za njeno žarište, odakle se ona širila dalje. [16 p15] Kuga koja se pojavila u Beogradu 1627. tumačena je kao Božija kazna za nemoral, ,jer su krčme bile pune prostitutki”. [17 p476] Bosanski franjevac Pavle Papić, koji se u vreme vrhunca epidemije (1628) zatekao u gradu, javio je Vatikanu: „Kada sam stigao u Beograd ovaj grad je bio zaražen kugom... Ne brinući se za sopstveni život, odmah sam otišao među obolele i nijedna od ovih ovčica božjih nije prešla na onaj svet bez ispovedi i pratnje do groba". [2 p105] Sudeći po njegovom navodu, franjevac se pre svega usmerio na pružanje pomoći hrišćanskim (katoličkim) stanovnicima, dok su muslimani bili i dalje prepušteni sugestijama svoje uleme.

Drugi ciklus epidemije kuge (1635-1666) nije, međutim, bio obeležen stalnim sukobima sa Austrijom, jednim od glavnih uzroka pojavi kuge u Beogradu. Time se nameće zaključak da tih decenija XVII veka kuga nije bitno uticala na pad broja žitelja Beograda. Ovo dokazuje i nekoliko izveštaja dubrovačkih poklisara, koji su s proleća 1665. boravili u Beogradu, gde se nalazio i veliki vezir, u trenutku kada je još uvek bila neizvesna sudbina Vašvarskog mira (sklopljenog 10. VIII 1664). U tim izveštajima se na ni jednom mestu ne pominje kuga. [18 pp496-526] Prema izveštaju katoličkog misionara (oko 1623) Beograd je imao 100.000 stanovnika. Nekoliko de- 
cenija kasnije (1675), u mletačkom itinerarijumu navedeno je da u gradu ima svega 1.200 kuća. Mlečanin Beneti, koji je grad posetio 1688, naveo je da u njemu živi 50.000 ljudi. [2 p90] Primetan pad broja stanovnika, što je navedeno za period kad na celom Levantu jenjava drugi talas kuge (oko 1660), može se dovesti u vezu sa tvrdnjom pojedinih istoričara po kome Beograd postaje žrtva ove epidemije tek nakon njenog velikog povlačenja sa evropskih i bliskoistočnih prostora, što je pospešila nova serija osmansko-austrijskih ratova.

Situacija se menja tokom Velikog turskog rata (1683-1699), kada Beograd počinje ozbiljnije da strada od kuge. Grad je septembra 1688. zauzela nemačka vojska, da bi 1690. Osmanlije uspele da povrate grad. [9] Ova promena gospodara ostavila je posledice i na strukturu njegovih stanovnika, jer je muslimanski deo morao da se iseli. Isti događaj ostavio je dobru pouku budućim naraštajima, zbog čega predstavlja glavni razlog nastanku serhada sa centrom u Beogradu, dok njegov muhafiz dobija široka ovlašćenja. [19 pp297-302] Sa pravom se može pretpostaviti da je u njegovu nadležnost prešao nadzor nad zdravstvenom zaštitom stanovništva, sa kompetencijama da može da zavede karantin po sopstvenom nahođenju.

U godini kada su Osmanlije uspele da povrate Beograd, kuga se već proširila značajnim delom Balkana. Njome su bili zahvaćeni Sarajevo, ali i cela Dalmacija. [20 p26] Godine epidemije tek su predstojale, a posebno se 1693. pokazala pogubnom. Tokom epidemije koja je te godine izbila, stradala je trećina stanovnika Carigrada. [9] Veliki pomor zahvatio je i Egipat, dok je u Kairu dnevno umiralo po 20.000 ljudi. [21 pp124-125] Ovom epidemijom bili su pogođeni Izmir, Alep, Jerusalim, Palestina, Galileja i druge oblasti. [9] Upravo je u leto te godine (1693) izvršen novi napad nemačke vojske na Beograd, koji je završen neuspešno, ali je predstavljao dovoljan povod za novi talas kuge. Kuga je i narednih godina ostala latentna pretnja gradu; nadživela je i sam sukob.

Kuga je 1700. pustošila okolinu Beograda, što je podstaklo Dvorski ratni savet u Beču da naredi uspostavljanje karantina i preduzimanje neophodnih mera na granici sa Osmanskim carstvom. [22 p159] Pokušaj vlasti u Beogradu da obuzdaju kugu, izazvala je oštru reakciju stanovnika u vezi prihvatanja ovih mera. Kada je Ali-paša Moralija, muhafiz Beograda, naredio obavezno sahranjivanje umrlih od kuge i uveo karantin, pobunili su se narod i vojska stacionirana u gradu. Tokom pobune 21. oktobra 1700. Ali-paša je rastrgnut na komade. [19 p306] Ovo je jedna od retkih vesti, koja ukazuje kako je stanovništvo (u prvom redu muslimani) reagovalo na uvođenje sanitarnih propisa, koji su se odnosili na zaštitu od ove epidemije.

Ovakav stav donekle se može dovesti u vezu sa činjenicom da su muslimani bili u mnogo manjoj meri podložni histeriji u slučaju epidemije, što su pojedine diplomate u svojim izveštajima isticale. [5] Interpretacijom ovakvih dokaza zaključuje da epidemija kod ovog dela stanovništva nije izazivala pometnju kao kod hrišćana. Ovo se može dovesti u vezu sa vekovima nametanim stavom uleme, koja je tumačila kugu kao Božiju volju, ujedno i kaznu, te ju je kao takvu trebalo i prihvatiti. S druge 
strane, hrišćani su, takođe, kugu doživljavali kao jednu vrstu Božije kazne, reagujući na nju načinom koji spada u domen sujeverja.

Kuga se u Beogradu ponovo javlja 1707. [22 p159] Ova epidemija nagnala je vlasti u Beču da prekinu saobraćaj sa osmanskim teritorijama. Najslabiju kariku je predstavljao Zemun, odakle je sa osmanske teritorije u Austriju ulazila sva roba. Na ovakve mere Austrija je bila naterana iz jednog vrlo važnog razloga. Po uvreženom shvatanju, koje je vladalo među medicinskim stručnjacima tokom XVIII veka, Ugarska je važila za najnezdraviju oblast Evrope, [23 p54] dok se pojava i brzo širenje zaraza objašnjavalo suvim vazduhom. Džejms Lind se u opravdanju ovoga pozivao na činjenicu da je vojska ugarskih pobunjenika (kuruca) od bolesti gubila polovinu svojih ljudi. [23 p54]

Po stavu pojedinih istraživača, kuga je tokom XVIII veka u mnogo većoj meri pustošila balkanske provincije, nego u prethodom periodu [4 p38]. Novi tursko-austrijski rat (1716-1718) ponovo je u prvi plan izbacio problem zaštite od epidemije, koja se sa vojskama neometano i sigurno širila. Džejms Lind naveo je da je tokom ovog rata 40.000 vojnika u austrijskoj vojsci stradalo usled „malignom izlaganju ugarskom vazduhu”, [23 p55] nagoveštavajući time da u njihovom stradanju prepoznaje određene oblike epidemija. Tokom leta 1717. i 1718. austrijskoj vojsci mnogo veći neprijatelj bile su epidemije, nego sami Turci. [23 p56]

Nakon ovog rata, Beograd je dospeo u posed Austrije, čija se teritorija po odredbama Požarevačkog mira (1718) približila Nišu. Prema pojedinim istoričarima, nakon austrijskog osvajanja nekoliko desetina hiljada muslimanskih stanovnika moralo je da se iseli, dok je u gradu ostao samo jedan musliman. [2 p112]. „Ulaskom u kulturnu sferu baroka Beograd je obezbedio onaj svoj budući karakter koji je otkrivao modernizacijske težnje i potrebu za trajnim uređenjem tragovima logike srednjeevropskih gradova”. [24 p120] Međutim, ovo je ujedno značilo da se granica Austrije pomerila duboko na Balkan, do Niša, zbog čega se objašnjava izostanak brige austrijskih vlasti na prevenciji kuge.

Beograd je ostao u posedu Austrije naredne 22 godine, da bi Beogradskim mirom (nakon rata 1737-1739) bio vraćen Osmanlijama. Česta promena gospodara i rušenja koja je grad tokom ratnih operacija pretrpeo, uticali su na pad broja stanovnika. Cirkulacija vojnika, regrutovanih u različitim delovima države, kao i nehigijenski uslovi, doprineli su da se kuga ponovo pojavi 1738. U jednom dokumentu iz ovog perioda navedeno je da „Od Zemuna do Varadina nije se moglo proći drugom od trupova mrtvih ljudi i skotova, i od smrada. A ne mogaše se ni Dunavu pristupiti ni vode zahvatiti od teškoga gada i smrada." [25 p455] Tokom opsade grada 1738, prema procenama očevidaca, u austrijskoj vojsci umiralo je dnevno 80 do 100 vojnika od kuge, malarije i dizenterije. [26 p126] Novi nalet kuge pogodio je grad već 1741 .

Nakon ovih nedaća, Beograd je sveden na grad od 9.500 stanovnika, od toga 6.000 Srba i 500 Jevreja. [14 p279] Teško je utvrditi koliko je kuga doprinela tome da se broj njegovih stanovnika drastično smanji. Nakon sklapanja Beogradskog mira (1739), ustrojstvo i funkcionisanje sanitarne službe prema austrijskom modelu pre- 
staje. Pojedini istraživači smatraju da je upravo kuga iz 1738, koja se naredne godine proširila po celoj Slavoniji, kao i epidemija koja izbija 1744. u okolini Siska, doprinela da austrijska vlast dovrši izgradnju sanitarnog kordona na Savi. [27 p386]

Kako su pojedini istraživači ukazali, sanitarni kordon je nastao iz očigledne potrebe da se susedne države zaštite od kuge, koja je dolazila sa osmanske teritorije. Habsburške vlasti su tokom XVI veka organizovale sanitarne službe. Ova početna nastojanja krunisana su tokom XVII veka sa nekoliko zakonodavnih akata, koji će postati osnovica sanitarnog zakonodavstva Vojne krajine u XVIII veku. [28 p98] Generalno se smatra da je sanitarni kordon osnovan Patentom Karla VI (1711-1740) od 22. oktobra 1728, koji je predviđao da „nasuprot turskim područjima treba zbog neposredne opasnosti od zaraznih bolesti urediti stalnu protuodbranu prilagođenu prema težini okolnosti”. [28 p99]

Duž reke Save organizovan je sistem karaula i čardaka da bi se kontrolisao prelaz sa osmanske na austrijsku teritoriju. Takođe, izgrađene su brojne kontumacije, koje su imale u svom sklopu i karantin. Najznačajnija kontumacija bila je smeštena u Zemunu. Kao jednu od mera koje je austrijska vlast preduzela bili su i „sanitatis exploratores", uhode ubacivane na osmansku teritoriju kako bi ispitivale zdravstvene prilike i o njima obaveštavale Beč. [22 p161] Ova činjenica dovoljno govori koliko su u Austriji strahovali od pojave kuge, ali i koliko je osmanska teritorija važila kao latentno izvorište ove epidemije, tako da je trebalo stalno motriti na nju.

Odmah nakon povratka Beograda pod vlast Osmanlija (1740), izbrisani su svi trgovi dvadesetdvogodišnje austrijske vladavine. Iz njega je „sva evropska kultura nestala", a on se ubrzo preobratio u orijentalni grad. [26 p104] Turci su u Beogradu 1740. zatekli samo 8 Srba i 45 Jevreja, dok je uskoro u njemu bilo naseljeno oko 2.000 Turaka. [244 p132] Novi rat tokom koga je Beograd ponovo pao pod austrijsku vlast (1789-1791) doprineo je pogoršanju prilika. Ponovo je muslimansko stanovništvo bilo primorano da beži. Prema pojedinim istoričarima, Beograd je krajem XVIII bio sveden na grad sa 2.500 kuća i oko 25.000 stanovnika. [2 p114] Poslednji veliki nalet kuge koji je iskusio desio se između 1812. i 1814. kada je on, zajedno sa Bukureštom, izgubio trećinu svojih stanovnika. Procenjuje se da je kuga u ovom naletu odnela 150.000 ljudi, izazvavši potpun prekid trgovine. Kao meru predostrožnosti, vlasti su otkazale sve vašare i panađure u ovoj oblasti [29 pp102-103], kako se kuga kroz komunikaciju ljudi ne bi dalje širila.

Beograd je tokom XIX veka nastavio da figurira na granici između dve države, koja se Aleksandru Kinglejku činila kao granica dva suprotna sveta. Tokom boravka u Zemunu on je još uvek osećao da pripada Evropi, dok je među svakodnevnom žargonu njegovih stanovnika prepoznavao sličnosti sa svetom iz koga je potekao. Sa namerom da pređe $u$ Beograd činilo mu se da odlazi $u$,veličanstvenost i pustoš Istoka”. [30 p1] Kako je u svom putopisu naveo „kuga i strah od kuge delila je ljude jedne od druge. Svi dolasci i odlasci prestajali su pred užasom žute zastave. Ukoliko bi se rešili da prekršite zakon karantina, bićete tretirani sa vojničkom užurbanošću." [30 
p2] On je bio u obavezi da prema nalogu austrijskih vlasti izdrži četrnaestodnevni karantin, pre nego što pređe na osmansku teritoriju. [30 p3]

Kuga je svakako predstavljala jedan od glavnih demografskih razloga, koji je uticao na dugotrajni pad stanovnika Beograda tokom XVIII i početka XIX veka. Iskazi putopisaca na kojima se dobrim delom temelji naše istraživanje potpuno se podudaraju sa ranije izrečenim tvrdnjama pojedinih istoričara koji su istraživali fenomen kuge na osmanskim prostorima. Oni su ukazali da je na severo-zapadnoj osmanskoj granici ona mnogo češće prisutna, nego na primer u jugozapadnim delovima Balkanskog poluostrva (na primer na Moreji).

U periodu od 1700. do 1850. ovaj deo osmanske teritorije pogodilo je 23 epidemije kuge, koja je trajala ukupno 59 godina. [31 pp189-199] Drugim rečima, u intervalu od 3 godine, kuga je trajala preko godinu dana. Upravo u ovoj zoni nalazio se i Beograd, zbog čega su i svi ratovi koje je osmanska vojska vodila sa austrijskom tokom navedenog perioda obavezno bili ispraćeni kugom. Isti period obeležilo je i prvo ozbiljnije nastojanje osmanskih vlasti da se izbori sa epidemijom, koje nije svuda dalo iste rezultate. [32 pp87-108] Zbog svega navedenog, stanovništvo Osmanskog carstva je trepelo mnogo veći mortalitet u slučaju pojave kuge, što je važilo i za Beograd.

\section{Zaključak}

Kuga u ranomodernom Beogradu postaje stalna pojava od vremena osmanskog osvajanja. Najveći problem istraživanju epidemiji kuge u Beogradu predstavlja nepostojanje adekvatnih istorijskih izvora, zbog čega se ne može sa potpunom sigurnošću utvrditi ritmika njene ubojitosti. Dodatno ovu problematiku opterećuje i izostanak redovnog popisivanja koje su praktikovale osmanske vlasti tokom XVII i XVIII veka, kada država prelazi na drugačiji sistem razrezivanja poreza. Sve ovo uticalo je da se o razmerama uticaja kuge na ukupan broj stanovnika Beograda površno nagađa. Od značaja je činjenica da od Velikog turskog rata tokom svih narednih osmansko-austrijskih sukoba kuga čini nezaobilaznu propratnu pojavu u Beogradu. Ovo je potpuno u skladu sa istraživanjem, koje je ukazalo da u periodu od 1700. do 1850. severoistočnu osmansku granicu (u koju je spadao i Beograd) pogađa 23 epidemija kuge, koje su ukupno trajale 59 godina. Za razliku od pojedinih delova Evrope u kojima je ona izazivala kolektivnu histeriju, kao manifestaciju opšte bede i nesigurnosti, slični slučajevi nisu zabeleženi u Beogradu. Osmanske vlasti u mnogome su zaostajale u primeni sanitarnih propisa, tako da je tokom cele ranomoderne epohe u tome prednjačila Austrija, koja je uspela da tokom XVIII veka završi izgradnju sanitarnog kordona prema Osmanskom carstvu. 


\section{Reference}

1. Коцић М. Оријентализација материјалне културе на Балкану. Османски период XV-XIX век. Београд: Филозофски факултет \& Hesperiaedu; 2010.

2. Samardžić R. Beograd pod Turcima. U Samardžić N - Samardžić R - Roter-Blagojević M priredili. Kulturna istorija Beograda. XVIII vek. Beograd: Hesperiaedu; 2014; 63-114.

3. Kocić M. Razvoj zdravstvene službe u Veneciji (Magistrato alla Sanità). Acta hist med stom pharm med vet. 2013;32;45-56.

4. Armağan L - Özden N. Procjena raznih epidemija kuge u balkanskim i zapadno-anadolskim krajevima Osmanskog carstva u 18. stoljeću. Prilozi istorijskog insituta u Sarajevu. 2005;35;31-43.

5. Kocić M. Diplomatija u službi kapitala: evropske nacije na osmanskom Levantu (XVIXVIII vek). Beograd: Hesperiaedu \& Filozofski fakultet; 2014.

6. Hrabak B. Talasi kuge na bosanskohercegovačkom upravnom prostoru 1463-1800. Acta hist med stom pharm med vet. 1989.29;19-36.

7. Храбак Б. Кужне редње у Босни и Херцеговини 1463-1800. Историјски зборник. 1981;2/2;5-41.

8. Bulmuş B. Plague, Quarantines and Geopolitics in the Ottoman Empire. Edinburgh: Edinburgh University Press; 2012.

9. Kocić M. Turska u međunarodnim odnosima 1688-1699: put u evropsku diplomatiju. Beograd: Hesperiaedu \& Filozofski fakultet; 2014.

10. Shefer-Mossensohn M. Ottoman Medicine: Healing and Medical Institutions, 1500-1700. Albany: State University of New York Press; 2009.

11. Panzac D. Quarantaines et lazarets. L'Europe et la peste d' Orient (XVIIe-XX siecles). Aix-en-Provence: Édisud; 1986.

12. Howard J. An account of the principal lazarettos in Europe. Warington: Printed by William Eyres; 1789.

13. Varlik N. Disease and Empire: A History of Plague Epidemics in the Early Modern Ottoman Empire (1453-1600). Chicago: University of Chicago Press; 2008.

14. Јачов М. Списи Тајног ватиканског архива XVI-XVIII века. Београд: САНУ; 1983.

15. Самарџић Р. Београд и Србија у делима француских савременика XVI-XVII век. Београд: Историјски архив Београда; 1961.

16. Cipolla CM. Cristofano and the Plague. A Study in the History of Public Health in the Age of Galileo. Berekeley-Los Angeles: University of California Press; 1973.

17. Пешаљ Ј. Између врача и лекара: обележја здравствене културе. U Фотић, Александар (pr.). Приватни живот у српским земљама у освит модерног доба. Београд: Clio; 2005; 475-504.

18. Радонић Ј. Дубровачка акта и повеље, књ. III, св. 1. Београд: СКА; 1939.

19. Тричковић Р. Списак мухафиза Београда од 1690. до 1789. године. Истор Час. 1971;18;297-327.

20. Радонић Ј. Дубровачка акта и повеље, књ. IV, св. 2. Београд: СКА; 1942.

21. Österreichisches Staatsarchiv, Haus- Hof- und Staatsarchiv, Handschrift, iot 132, bohum 1020 , band 6 . 
22. Skenderović R, Kuga u Požegi i Požeškoj kotlini 1739. godine. Scrinia Slavonica; 2003;3;157-170.

23. Lind J. Two Papers on Fevers and Infection Which were read before Philosophical and Medical Society in Edinburgh. London: Printed for D. Wilson; 1762.

24. Samardžić N. Barokni Beograd. U Kulturna istorija Beograda. XVIII vek; 117-143.

25. Поповић ДJ. Срби у Војводини, vol. II. Нови Сад: Матица Српска; 1959.

26. Aksan V. Ottoman Wars, 1700-1870. An Empire Besieged. New York: Routlege; 2007.

27. Barlé J. Kuga u požeškoj okolini 1739. Liječ vjes 28(11);1906.

28. Samardžija Z. Habsburško vojno zdravstvo u Slavoniji i Srijemu do ukidanja vojne krajine. Acta hist med stom pharm med vet. 2013;32;95-119.

29. Chakravarti A. Institutions, Economic Performance and the Visible Hand: Theory and Evidence. Gheltenham: Edward Elgar Publishing Limited; 2012.

30. Kinglake AW. Eōthen: Or Traces of Travel Brought Home from the East. New York: George P. Puntam; 1849.

31. Panzac D. La peste dans l' Empire ottoman 1700-1850. Louvain: Peelers; 1985.

32. Panzac D. Politique sanitarie et fixation des frontiers: l'exemple ottoman (XVIIIe-XIXe). Turcica; 1999;31;87-108.

\section{Summary}

Plague in early modern Belgrade becomes a constant occurrence since the time of the Ottoman conquest. The biggest problem of the research of the plague epidemic in Belgrade is the lack of adequate historical sources, so the rhythm of its deadliness can not be determined with absolute certainty. In addition, this issue is burdened with lack of regular censuses taken by the Ottoman authorities during the $17^{\text {th }}$ and $18^{\text {th }}$ centuries, when the state had moved to a different system of levying taxes. The scale of the impact of the plague on the total population of Belgrade could therefore be only speculated. Important fact is that since the Great Turkish War, during all subsequent Ottoman-Austrian conflicts, plague seems unavoidable visitor of Belgrade. This is fully in line with the research, which showed that in the period from 1700 to 1850 , the Ottoman northeastern border (which Belgrade belonged to) was affected by 23 plagues, which lasted for a total of 59 years. Unlike some parts of Europe, where it caused a collective hysteria, as a manifestation of the general misery and uncertainty, similar cases have not been recorded in Belgrade. The Ottoman state greatly lagged behind Europe in the implementation of sanitary regulations, so it was completely surpassed by Austria in the early modern era, as Austria had managed to finish the construction of a sanitary corridor towards the Ottoman Empire in the $18^{\text {th }}$ century.

Rad primljen: 2. 8. 2014.

Recenziran: 5. 9. 2014.

Prihvaćen: 29. 9. 2014. 